\title{
Comparative Effectiveness of Tocilizumab and TNF Inhibitors in Rheumatoid Arthritis Patients: Data from the Rheumatic Diseases Portuguese Register, Reuma.pt
}

\author{
Vasco C. Romão, ${ }^{1,2}$ Maria José Santos, ${ }^{2,3}$ Joaquim Polido-Pereira,,2 \\ Cátia Duarte, ${ }^{4}$ Patrícia Nero, ${ }^{5}$ Cláudia Miguel, ${ }^{6}$ José António Costa, ${ }^{7}$ \\ Miguel Bernardes, ${ }^{8}$ Fernando M. Pimentel-Santos, ${ }^{5,9}$ Filipe Barcelos, ${ }^{6}$ \\ Lúcia Costa, ${ }^{8}$ José António Melo Gomes, ${ }^{6}$ José Alberto Pereira da Silva, ${ }^{1}$ \\ Jaime Cunha Branco, ${ }^{5,9}$ José Canas da Silva, ${ }^{3}$ José António Pereira da Silva, ${ }^{4}$ \\ João Eurico Fonseca, ${ }^{1,2}$ and Helena Canhão ${ }^{1,2}$ \\ ${ }^{1}$ Rheumatology Research Unit, Instituto de Medicina Molecular, Faculdade de Medicina da Universidade de Lisboa, \\ Lisbon Academic Medical Centre, Edifício Egas Moniz, Avenida Prof. Egas Moniz, 1649-028 Lisboa, Portugal \\ ${ }^{2}$ Rheumatology Department, Hospital de Santa Maria, Lisbon Academic Medical Centre, Avenida Prof. Egas Moniz, \\ 1649-028 Lisboa, Portugal \\ ${ }^{3}$ Rheumatology Department, Hospital Garcia de Orta, Avenida Prof. Torrado da Silva, 2801-951 Almada, Portugal \\ ${ }^{4}$ Rheumatology Department, Centro Hospitalar Universitário de Coimbra, Praceta Mota Pinto, \\ 3000-076 Coimbra, Portugal \\ ${ }^{5}$ Rheumatology Department, Hospital Egas Moniz, Centro Hospitalar Lisboa Ocidental, Rua da Junqueira 126, \\ 1349-019 Lisboa, Portugal \\ ${ }^{6}$ Rheumatology Department, Instituto Português de Reumatologia, R. Beneficência 7, 1050-034 Lisboa, Portugal \\ ${ }^{7}$ Rheumatology Department, Unidade Local de Saúde do Alto Minho, Hospital Conde de Bertiandos, \\ Largo Conde de Bertiandos, 4990-041 Ponte de Lima, Portugal \\ ${ }^{8}$ Rheumatology Department, Centro Hospitalar São João, Alameda Prof. Hernâni Monteiro, 4200-319 Porto, Portugal \\ ${ }^{9}$ CEDOC, NOVA Medical School, Nova University, Campo dos Mártires da Pátria 130, 1169-056 Lisboa, Portugal
}

Correspondence should be addressed to Helena Canhão; helenacanhao@gmail.com

Received 5 December 2014; Accepted 11 February 2015

Academic Editor: Guixiu Shi

Copyright (c) 2015 Vasco C. Romão et al. This is an open access article distributed under the Creative Commons Attribution License, which permits unrestricted use, distribution, and reproduction in any medium, provided the original work is properly cited.

Objectives. To compare the effectiveness of TNF inhibitors (TNFi) and tocilizumab in rheumatoid arthritis (RA) treatment, according to different response criteria. Methods. We included RA patients registered in the Rheumatic Diseases Portuguese Register treated with TNFi or tocilizumab for at least 6 months, between January 2008 and July 2013. We assessed remission/low disease activity (LDA) at 6 months according to DAS28, CDAI, and SDAI, as well as Boolean ACR/EULAR remission and EULAR response rate, adjusting for measured confounders. Results. Tocilizumab-treated patients $(n=95)$ presented higher baseline disease activity and were less frequently naïve to biologics compared to TNFi users $(n=429)$. Multivariate logistic regression analysis including the propensity score for receiving tocilizumab showed that patients treated with tocilizumab were more likely to achieve remission or LDA according to DAS28 (OR = 11.0/6.2, 95\% CI 5.6-21.6/3.2-12.0), CDAI (OR = 2.8/2.6, 95\% CI 1.2-6.5/1.3-5.5), or SDAI $(\mathrm{OR}=$ 3.6/2.5, 95\% CI 1.5-8.7/1.1-5.5), as well as a good EULAR response (OR = 6.4, 95\% CI 3.4-12.0). However, both groups did not differ in Boolean remission $(\mathrm{OR}=1.9,95 \%$ CI $0.8-4.8)$ or good/moderate EULAR response (OR = 1.8, 95\% CI 0.8-4.5). Conclusions. Compared with TNFi, tocilizumab was associated with greater likelihood of achieving DAS28, CDAI, and SDAI remission/LDA and EULAR good response. Boolean remission and EULAR good/moderate response did not differ significantly between groups. 


\section{Introduction}

Tumour necrosis factor inhibitors (TNFi) were the first biological agents introduced in the treatment of rheumatoid arthritis (RA). They have been widely used for over 15 years now and extensive evidence of their efficacy and effectiveness has accumulated, arising from numerous randomised clinical trials (RCTs) and large observational studies [1-6]. Tocilizumab, a monoclonal antibody targeting the interleukin-6 receptor, has become available one decade later and has progressively gained its place into RA treatment algorithms [7]. It has now been included in the last 2013 European League Against Rheumatism (EULAR) recommendations as one of the potential first line biologic drugs, alongside TNFi [7], after methotrexate (MTX) and/or other synthetic diseases modifying antirheumatic drugs (DMARDs) failure, a guidance followed by several national rheumatology societies [8].

TNFi are highly efficacious, both in monotherapy and in combination with synthetic DMARDs, such as MTX. Several indirect comparisons of RCTs and register-based observational studies failed to show significant differences in effectiveness between TNFi, although there are no available RCTs specifically addressing this issue [3-6, 9-12]. Likewise, tocilizumab presents good response rates, not only with concomitant MTX, but also in monotherapy $[13,14]$. The only available head-to-head study, comparing tocilizumab and adalimumab in monotherapy, revealed higher clinical response with the former [15]. While RCTs directly assessing both classes of drugs in combination with synthetic DMARDs are missing, indirect comparisons through systematic reviews of RCTs have reported similar American College of Rheumatology (ACR) 50 responses [11, 12, 16-19] between tocilizumab and TNFi, with only one of these studies suggesting a higher ACR70 response rate with tocilizumab [16].

Real life observational data have confirmed the effectiveness of tocilizumab, with studies reporting $39-54.9 \%$ of the patients achieving remission according to disease activity score-28 joints (DAS28) [20-22] and 50.7\% reaching ACR50 response at 24 weeks [22]. However, there are few observational register-based studies comparing the effectiveness of different biologic drug classes in real life circumstances. In one of such studies, Yoshida et al. compared the remission rates after 6 months of treatment with tocilizumab or TNFi and found that although the percentage of patients reaching DAS28-erythrocyte sedimentation rate (ESR) remission was higher with tocilizumab, the rates of stringent Boolean remission were similar in both groups [23]. This finding reflects the profound effect of tocilizumab upon inflammatory markers, due to the direct inhibition of IL-6, a major activator of the acute phase response [24]. Thus, response rates to tocilizumab might be overestimated when considering composite scores that include inflammatory markers, such as the DAS28, where ESR or C-reactive protein (CRP) has a high weight on the overall score [24].

With this in mind, we aimed to compare the effectiveness of TNFi and tocilizumab in RA treatment, according to different response criteria, in patients followed for at least 6 months in a multicentre nationwide cohort. We further looked at assessing the impact of previous biologic therapies on treatment response.

\section{Methods}

2.1. Patients. The Rheumatic Diseases Portuguese Register, Reuma.pt, is a nationwide clinical register established in 2008 and used in daily practice by nearly all rheumatology centers in Portugal [25]. Biologic therapy for RA has been available in Portugal since 2000, with the introduction of etanercept and infliximab. Adalimumab was approved in 2003 and the three drugs currently account for the majority of treatments. Tocilizumab and golimumab have become available in 2009 and 2010, respectively, and have progressively been incorporated into the daily clinical practice. The decision to initiate, switch, or maintain biologic treatment is guided by the SPR recommendations [8], which make no formal statement about which agent(s) should be considered as first line option(s).

We included patients fulfilling ACR 1987 revised RA criteria, starting tocilizumab or TNFi (adalimumab, etanercept, golimumab, or infliximab; certolizumab was not available in Portugal during the time frame of the study) between January 2008 and July 2013, who were treated for at least 6 months and had available DAS28 scores at baseline and follow-up.

All patients provided written informed consent as part of their enrolment in Reuma.pt, which is approved by competent authorities in Portugal, including the Health National Directorate and the National Board of Data Protection. The study was conducted according to the Declaration of Helsinki, as revised in Fortaleza (October 2013) and was approved by the Santa Maria Hospital Ethics Committee.

2.2. Statistical Methods. The coprimary outcomes were the proportion of patients in remission according to DAS28 (<2.6), CDAI ( $\leq 2.8)$, SDAI $(\leq 3.3)$, and ACR/EULAR Boolean criteria (tender joint count-28 joints (TJC28) $\leq 1$, swollen joint count-28 joints (SJC28) $\leq 1, \mathrm{CRP} \leq 1 \mathrm{mg} / \mathrm{dL}$, and patient global health $(\mathrm{PGH}) \leq 1 / 10)$. Secondary outcomes included proportion of patients reaching at least low disease activity (LDA) according to DAS28 (<3.2), CDAI (CDAI $\leq 10)$, and SDAI ( $\leq 11)$; frequencies of EULAR good (change in DAS28 > 1.2 and DAS28- 6 months $\leq 3.2$ ) and good/moderate response (change in DAS28 $>0.6$ and DAS28-6 months $\leq 5.1$ or change in DAS28 > 1.2 and DAS28 > 5.1); and, finally, change in DAS28, ESR, TJC28, SJC28, visual analogue scale (VAS), and health assessment questionnaire (HAQ). Covariates of interest included age at biologic start, gender, race (Caucasian versus non-Caucasian), disease duration, years of education, seropositivity (if anti-citrullinated protein antibody (ACPA) and/or rheumatoid factor (RF) positive), erosive disease (if erosions identified at X-rays of hands/feet at any time in disease), previous biologic therapy status (biologicnaïve versus previously exposed to $\geq 1$ biologic), number of previous biologics, smoking status (current smokers versus noncurrent smokers), cardiovascular comorbidity (hypertension, dyslipidaemia, heart disease, or diabetes mellitus), and concomitant MTX and corticosteroid therapy. At 6 months, 
data were collected on TJC/SJC28, ESR, CRP, VAS (PGH and physician global assessment (PhGA)), and HAQ.

Baseline and follow-up data were compared according to biologic treatment using ANOVA, Student's $t$-test or chi-square tests, where applicable, both for each biologic separately and for biologic class (TNFi/tocilizumab). Bonferroni tests were applied, when significant differences were detected in ANOVA. We further performed stratification on previous biologic therapy status, to account for the potential relationship between previous biologic therapies and current therapy effectiveness.

To try to accommodate for patient- and disease-related confounders, we used multiple logistic regression and propensity score-based methods to explore the relationship between biologic class and treatment response. We built logistic regression models predicting binary response outcomes using stepwise backward elimination, including covariates with $P$ value $<0.1$ in the univariate analysis and those thought to be clinically meaningful (age, sex, seropositivity, number of previous biologics, disease duration, and baseline disease activity). In order to avoid overadjusting, individual components of the disease activity score were not considered. Variables conferring a greater than $10 \%$ change on the main regression coefficient (biologic class) were included in the final model.

A propensity score estimating the likelihood of receiving tocilizumab was generated, using a logit function and including baseline variables potentially related to biologic class that did not contain significant numbers of missing values: age, age-squared, sex, number of previous biologics, disease duration, baseline DAS28, TJC, SJC and concomitant treatment with MTX, corticosteroids, and other DMARDs. We then included this propensity score as a covariate in the univariate and multivariate logistic regressions in order to account for potential residual confounding. Finally, we conducted caliper 1:5 matching with replacement on the propensity score using the psmatch 2 command of Stata for each of the outcomes separately. Matching strategies significantly reduced the overall mean bias (e.g., 5.4\% for the DAS28 matching), while decreasing the number of patients subject to the analysis, as expected.

All statistical analyses were performed using Stata version 12.1 (StataCorp, College Station, TX, USA) and $P$ value was considered significant at $<0.05$.

\section{Results}

Five hundred and twenty-four patients fulfilled the inclusion criteria, 95 treated with tocilizumab and 429 with TNFi (106 adalimumab, 202 etanercept, 43 golimumab, and 78 infliximab). The baseline characteristics of the population are represented in Table 1. Patients from different groups had similar demographic characteristics, with expected distributions of variables such as age, gender, disease duration, smoking, or cardiovascular comorbidities, compatible with an established RA population. Frequencies of seropositivity (RF and/or ACPA), erosive disease and concomitant treatment with MTX, or low-dose corticosteroids were similar between groups considering either each biologic separately or biologic class. However, tocilizumab-treated patients were less frequently naïve to biologic therapy, had received a higher number of previous biologic agents, and had more active disease, as translated by significantly higher SJC28, PhGA, DAS28, CDAI, and SDAI. Furthermore, comparing patients by biologic class revealed higher mean ESR/CRP and increased proportions of patients with high disease activity according to all indexes in the tocilizumab group.

At follow-up (Table 2), only DAS28 and ESR were lower in the tocilizumab group compared to all TNFi $(P<0.001)$. Bonferroni tests after ANOVA regarding CRP at 6 months revealed that there were no significant differences between tocilizumab and each TNFi separately $(P>0.05$ for all twogroup comparisons). All other disease activity measures were similar between the groups. However, considering changes from baseline values, tocilizumab users presented a significantly greater decrease in DAS28, CDAI, SDAI, and inflammatory markers (ESR and CRP), as well as in the SJC28 and PhGA than patients treated with TNFi (Table 2).

3.1. Remission and EULAR Response. More than half of tocilizumab-treated patients were in DAS28 remission at 6 months, a significantly higher proportion than observed for TNFi users $(\mathrm{OR}=4.4,95 \%$ confidence interval $(\mathrm{CI}) 2.8-7.0$; Figure 1(a)). However, no significant differences were seen for remission rates according to CDAI (OR $=1.6,95 \%$ CI 0.8 3.2), $\mathrm{SDAI}(\mathrm{OR}=1.9,95 \% \mathrm{CI}$ 0.97-3.9), or Boolean definition $(\mathrm{OR}=1.1,95 \%$ CI $0.6-2.3)$ criteria. Similarly to DAS28 change and remission, nearly two-thirds of the tocilizumab group had a good EULAR response, compared to one-third of TNFi users $(\mathrm{OR}=3.6,95 \% \mathrm{CI}$ 2.3-5.7; Figure 1(b)). When considering the achievement of good/moderate EULAR response, the differences between groups were smaller, with $89.5 \%$ and $79.9 \%$ for tocilizumab and TNFi groups, respectively (OR = $2.1,95 \%$ CI 1.07-4.2, $P=0.03$ ).

3.2. Response according to Previous Exposure to Biologics. Stratification according to previous biologic therapy exposure revealed that biologic-naïve patients treated with tocilizumab had higher odds of achieving remission, not only according to DAS28 (OR $=7.6,95 \% \mathrm{CI} 4.0-14.5$ ), but also according to CDAI (OR $=2.6,95 \%$ CI $1.2-5.8)$ and SDAI $(\mathrm{OR}=3.0,95 \%$ CI 1.3-6.8; Figure 2(a)). No significant differences were seen with the more stringent Boolean definition ( $\mathrm{OR}=1.6,95 \%$ CI 0.7-3.7; Figure 2(a)). Regarding EULAR response, 76.9\% of biologic-naive patients in the tocilizumab group presented a good response, compared to $35.1 \%$ of TNFi users (OR = 6.2, 95\% CI 3.2-12.1; Figure 2(b)). Considering patients previously exposed to biologic therapy and although the numbers are considerably smaller ( $\mathrm{TNFi}=64$ and tocilizumab $=43$ ), the results were similar to those observed in the overall population analysis, with significant differences being seen only for DAS28 remission (OR = 2.8, 95\% CI 1.2-6.6; Figure 2(a)). Likewise, rates of EULAR response in this subgroup of patients were lower in comparison to those that were biologic-naïve, namely, $48.8 \%$ and $23.4 \%$ of EULAR good response in the tocilizumab and TNFi groups, respectively 


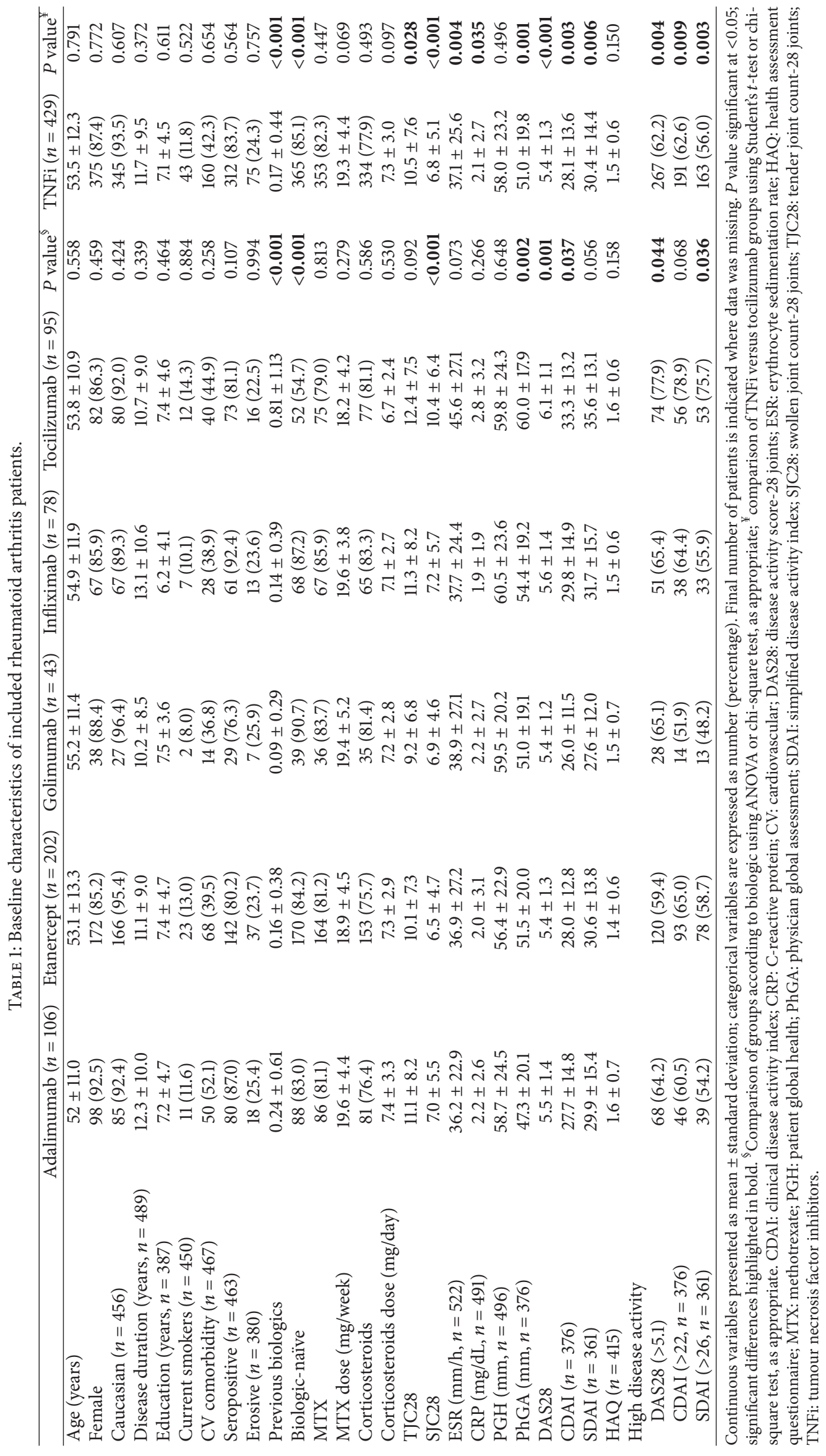




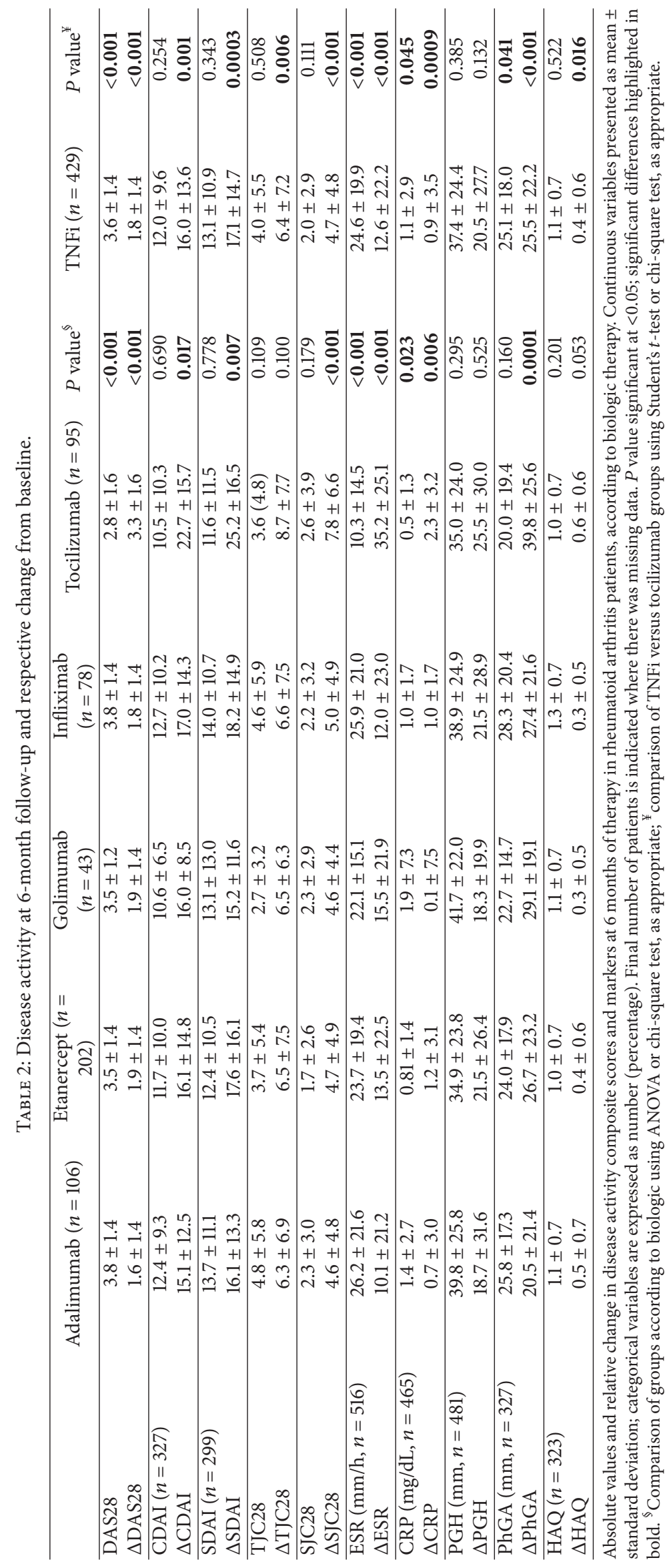




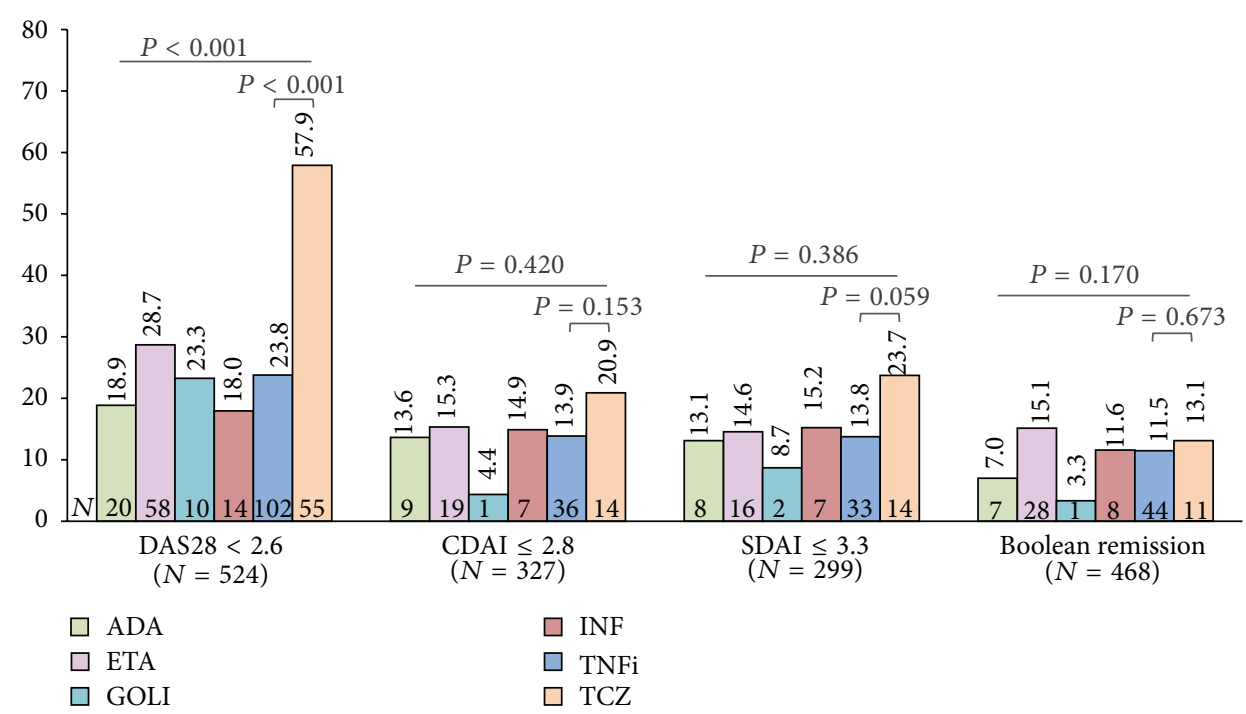

(a)

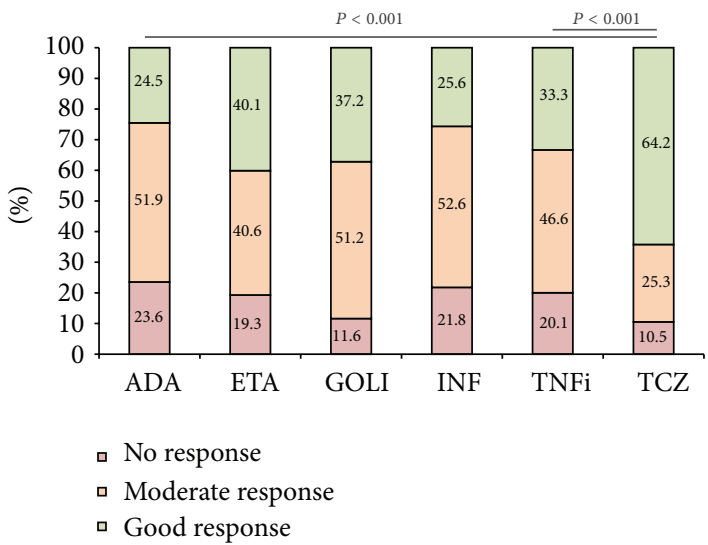

(b)

Figure 1: Frequencies of remission (a) and EULAR response (b) at 6 months according to biologic treatment. Tocilizumab- (TCZ-) treated patients had higher rates of DAS28 remission and EULAR response. Similar proportions of TCZ and TNFi users were in remission according to CDAI, SDAI, and Boolean remission criteria. $P$ value significant at <0.05. ADA: adalimumab; ETA: etanercept; GOLI: golimumab; INF: infliximab.

$(\mathrm{OR}=3.1,95 \%$ CI 1.4-7.1). Considering the achievement of at least a moderate EULAR response, differences between groups were less striking, being significant only in the biologic-naïve subgroup $(\mathrm{OR}=5.3,95 \% \mathrm{CI} 1.3-22.4, P=$ 0.011 ) and not in patients previously exposed to biologics $(\mathrm{OR}=2.3,95 \%$ CI $0.9-5.7, P=0.075)$.

3.3. Low Disease Activity at 6 Months. The proportions of patients achieving, at 6 months, at least a LDA state according to each of the indexes are represented in Figure 3 ((a) overall population analysis; (b) stratifying on previous biologic status). Notably, more than half of the patients reached LDA according to CDAI $(\leq 10)$ or SDAI $(\leq 11)$ regardless of type of treatment. As seen for remission, in the overall population analysis there were significant differences between groups favoring tocilizumab only for the DAS28 definition of LDA $(\mathrm{OR}=2.6,95 \%$ CI 1.6-4.1; Figure 3(a)). Interestingly, there was a better concordance between indexes than for remission, particularly in the tocilizumab group, with $64 \%$ of patients in LDA/remission according to every definition. Biologic-naïve patients also had higher odds of achieving at least a LDA state when treated with tocilizumab, compared to those in the TNFi group: defined by DAS28 (OR = 4.6, 95\% CI 2.4-9.0), CDAI (OR $=2.8,95 \%$ CI $1.3-6.1)$, or SDAI (OR $=2.5,95 \%$ CI 1.1-5.7; Figure 3(b)). As for patients previously exposed to biologics, there were no statistically significant differences between both drug classes in terms of achieving at least LDA according to any of the criteria (Figure 3(b)).

3.4. Multivariate Analyses. Table 3 presents the results of logistic regression and propensity scores-based analyses to determine the effect size of tocilizumab versus TNFi in predicting each of the discussed outcomes. Multivariate logistic regression, adjusting for age, disease duration, baseline 


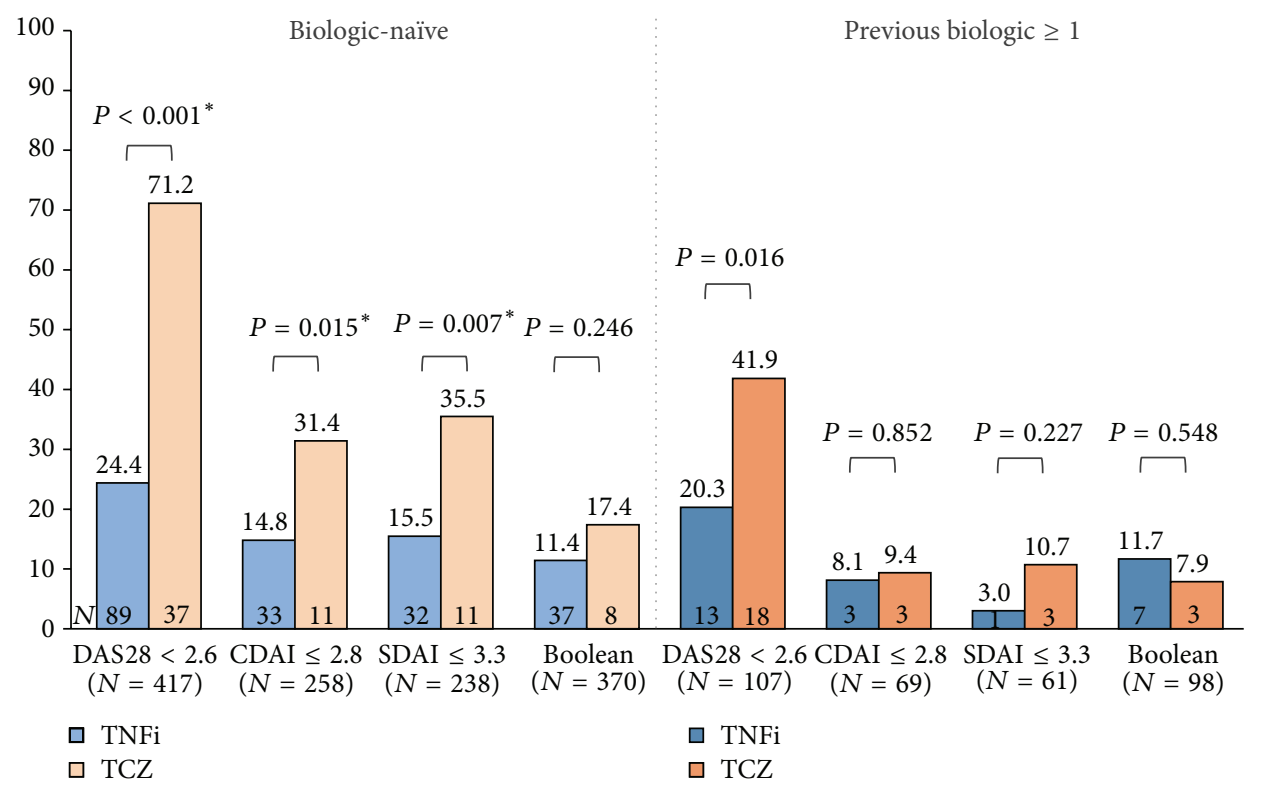

(a)

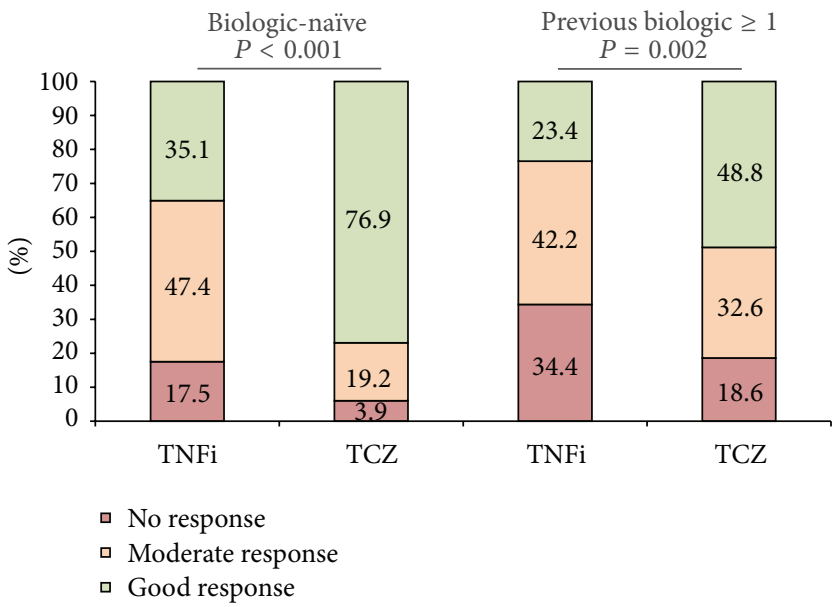

(b)

FIGURE 2: Remission (a) and EULAR response rate (b) at 6 months stratified by previous biologic therapy. (a) Biologic-naïve patients treated with TCZ had significantly higher rates of DAS28, CDAI, and SDAI remission, with nonsignificant differences in the more stringent Boolean remission. TCZ-treated patients previously exposed to at least 1 biologic had greater frequencies of DAS28 remission than those treated with TNFi, with similar rates of CDAI, SDAI, and Boolean remission. (b) EULAR response rates were significantly higher in the TCZ group for both previous biologic statuses, although the differences were greater in biologic-naïve patients. $P$ value significant at $<0.05$.

disease activity (DAS, CDAI, or SDAI, as appropriate), and number of previous biologics, revealed that tocilizumabtreated patients had higher odds of achieving remission and LDA according to DAS28, CDAI, and SDAI. There were no significant effects of biologic class on reaching Boolean remission. Good and good/moderate EULAR responses were also more likely to occur in tocilizumab-treated patients using this approach. The inclusion of the propensity scores predicting biologic class into the logistic regression model decreased the effect size of treatment group on the outcomes, although not changing the inference made for DAS28, CDAI or SDAI remission/LDA, Boolean remission, or EULAR good response. However, the odds of achieving a good/moderate EULAR response were no longer different between biologic therapy classes. Propensity score matching alone or in combination with multivariate logistic regression confirmed this finding and further revealed no significant effect of biologic class on reaching LDA according to SDAI. Achieving CDAI remission or LDA was not different between groups in the propensity score-matched analysis, although the regression analysis performed in the matched population did reveal significant differences for reaching remission/LDA, favoring TCZ. All other outcomes remained unchanged using this approach. 


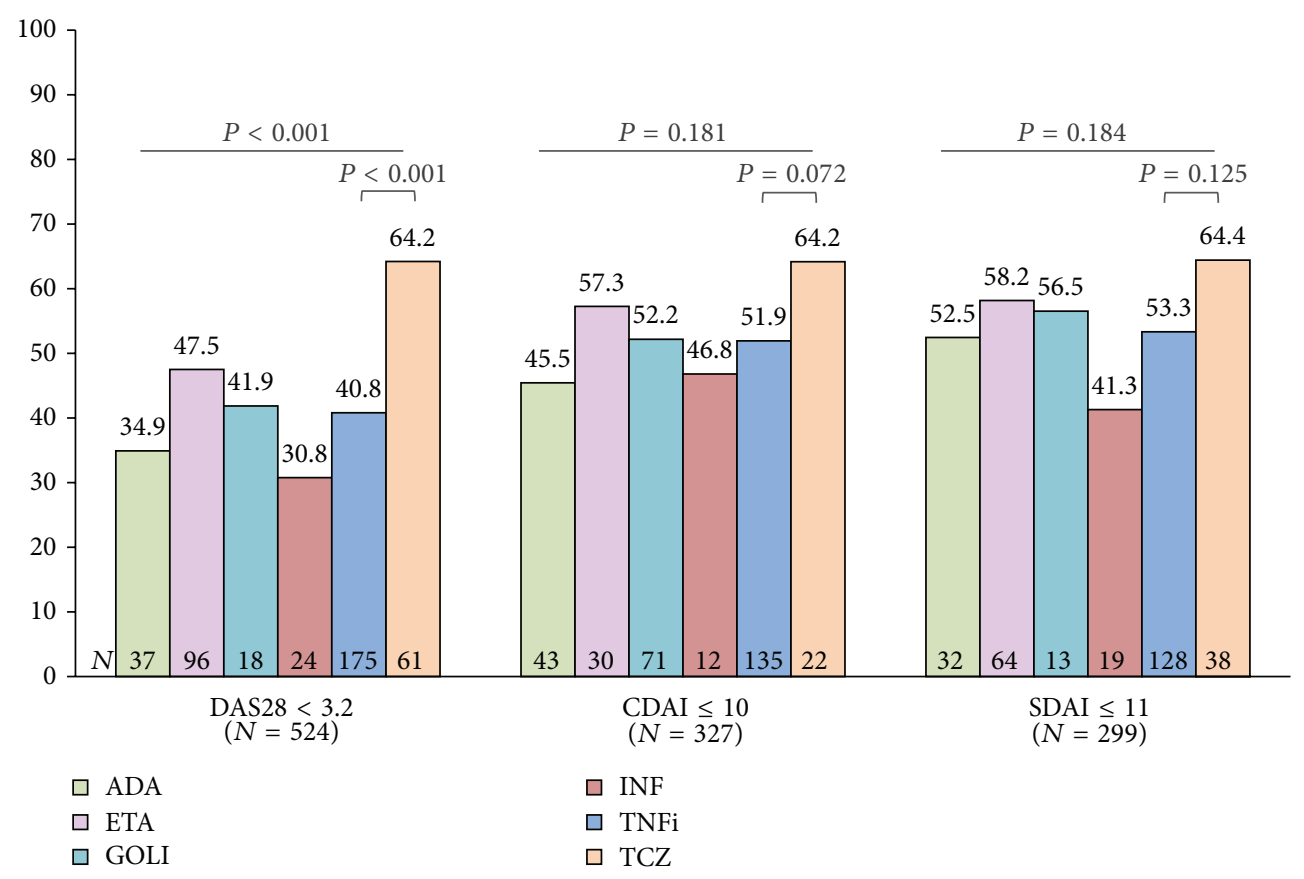

(a)

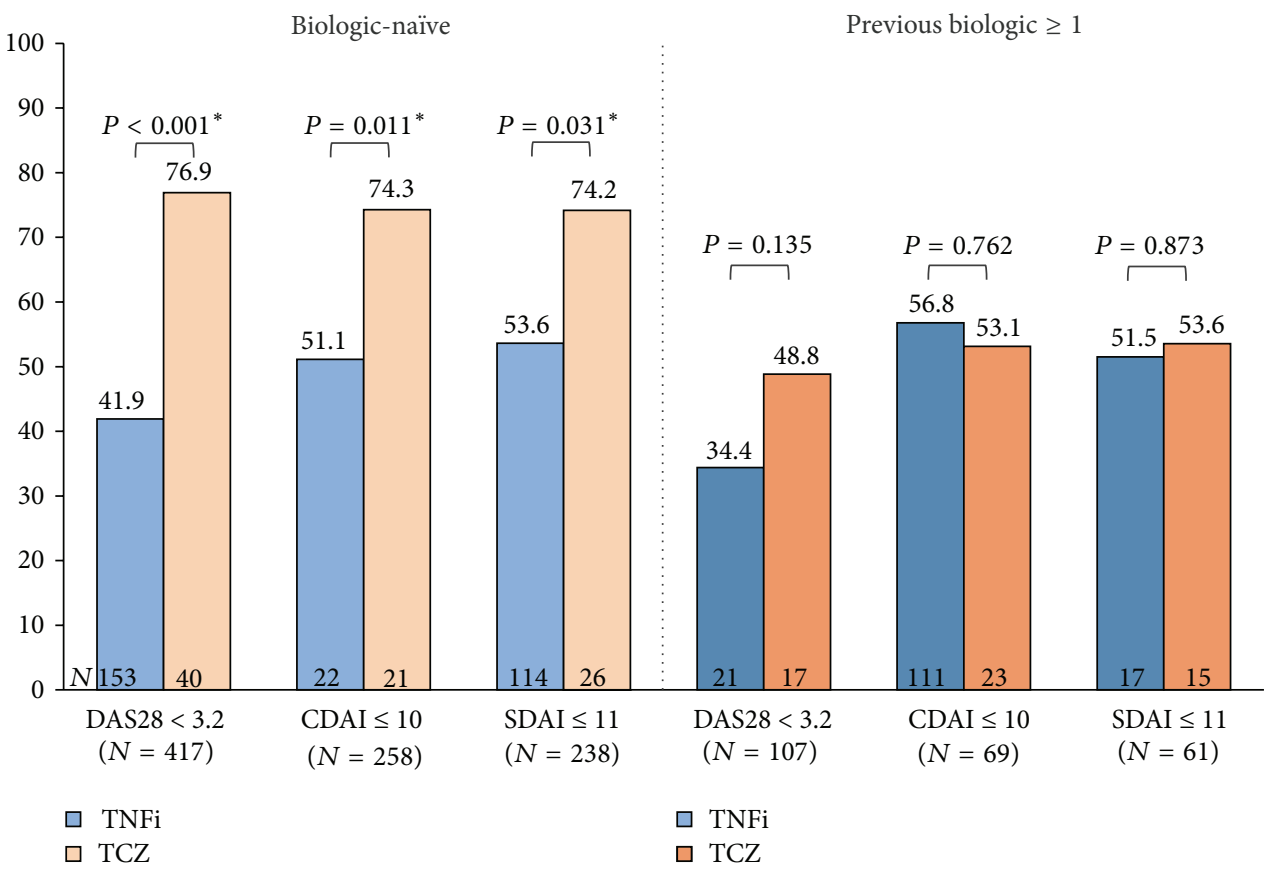

(b)

Figure 3: Low disease activity at 6 months according to treatment (a) and previous biologic therapy (b). (a) Significantly more patients treated with TCZ reached a state of at least DAS28 low disease activity (LDA), with no significant differences for CDAI and SDAI cutoffs. (b) Biologic-naïve patients in the TCZ group had significantly higher proportions of DAS28, CDAI, and SDAI LDA compared to TNFi users. On the contrary, in patients previously exposed to at least 1 biologic the frequencies of LDA according to all indexes were similar between drug class groups. $P$ value significant at $<0.05$.

\section{Discussion}

In this study we compared the effectiveness of two classes of biologic therapies in RA patients registered in our national register, Reuma.pt. We found that patients treated with tocilizumab were more likely to achieve DAS28, CDAI, and SDAI remission/LDA, as well as good EULAR response at 6 months, when adjusting for confounding factors. On the 
TABLE 3: Logistic regression and propensity score-based analyses to predict treatment response with tocilizumab versus TNFi.

\begin{tabular}{|c|c|c|c|c|c|c|c|}
\hline & \multirow{2}{*}{$N$} & \multicolumn{3}{|c|}{ Remission } & \multicolumn{3}{|c|}{ Low disease activity } \\
\hline & & Odds ratio & $95 \% \mathrm{CI}$ & $P$ value & Odds ratio & $95 \%$ CI & $P$ value \\
\hline & & \multicolumn{3}{|c|}{ DAS28 $<2.6$} & \multicolumn{3}{|c|}{ DAS28 $<3.2$} \\
\hline Multivariate LR & 489 & 13.3 & $6.9-25.4$ & $<0.001$ & 7.3 & $3.9-13.6$ & $<0.001$ \\
\hline Univariate LR + PS & 489 & 8.3 & $4.4-15.4$ & $<0.001$ & 5.5 & $2.9-10.5$ & $<0.001$ \\
\hline Multivariate LR + PS & 489 & 11.0 & $5.6-21.6$ & $<0.001$ & 6.2 & $3.2-12.0$ & $<0.001$ \\
\hline PS matching & 259 & 7.9 & $4.3-14.6$ & $<0.001$ & 5.0 & $2.7-9.2$ & $<0.001$ \\
\hline \multirow[t]{2}{*}{$\begin{array}{l}\text { PS matching + } \\
\text { multivariate LR }\end{array}$} & 259 & 12.3 & $6.0-25.4$ & $<0.001$ & 7.5 & $3.7-15.1$ & $<0.001$ \\
\hline & & \multicolumn{3}{|c|}{$\mathrm{CDAI} \leq 2.8$} & \multicolumn{3}{|c|}{$\mathrm{CDAI} \leq 10$} \\
\hline Multivariate LR & 308 & 2.9 & $1.3-6.6$ & 0.009 & 3.0 & $1.5-6.1$ & 0.002 \\
\hline Univariate LR + PS & 308 & 2.5 & $1.1-5.6$ & 0.022 & 2.3 & $1.1-4.6$ & 0.019 \\
\hline Multivariate LR + PS & 308 & 2.8 & $1.2-6.5$ & 0.016 & 2.6 & $1.3-5.5$ & 0.010 \\
\hline PS matching & 179 & 2.1 & $0.92-5.0$ & 0.078 & 2.0 & $1.00-4.1$ & 0.048 \\
\hline $\begin{array}{l}\text { PS matching + } \\
\text { multivariate LR }\end{array}$ & 179 & 3.3 & $1.3-8.4$ & 0.015 & 2.6 & $1.2-5.6$ & 0.017 \\
\hline & & \multicolumn{3}{|c|}{$\mathrm{SDAI} \leq 3.3$} & \multicolumn{3}{|c|}{$\mathrm{SDAI} \leq 11$} \\
\hline Multivariate LR & 282 & 4.1 & $1.7-9.5$ & 0.001 & 2.9 & $1.4-6.3$ & 0.005 \\
\hline Univariate LR + PS & 282 & 3.1 & $1.3-7.0$ & 0.008 & 2.2 & $1.04-4.8$ & 0.038 \\
\hline Multivariate LR + PS & 282 & 3.6 & $1.5-8.7$ & 0.005 & 2.5 & $1.1-5.5$ & 0.024 \\
\hline PS matching & 158 & 2.6 & $1.1-6.4$ & 0.029 & 1.6 & $0.8-3.5$ & 0.209 \\
\hline $\begin{array}{l}\text { PS matching + } \\
\text { multivariate LR }\end{array}$ & 158 & 4.0 & $1.5-10.8$ & 0.007 & 2.2 & $0.95-5.0$ & 0.065 \\
\hline \multicolumn{8}{|c|}{ Boolean } \\
\hline Multivariate LR & 442 & 2.1 & $0.91-4.8$ & 0.083 & & & \\
\hline Univariate LR + PS & 442 & 1.8 & $0.76-4.0$ & 0.184 & & & \\
\hline Multivariate LR + PS & 442 & 1.9 & $0.77-4.8$ & 0.159 & & & \\
\hline PS matching & 216 & 1.2 & $0.54-2.9$ & 0.629 & & & \\
\hline $\begin{array}{l}\text { PS matching + } \\
\text { multivariate LR }\end{array}$ & 216 & 1.4 & $0.54-3.9$ & 0.463 & & & \\
\hline & & \multicolumn{3}{|c|}{ Good EULAR } & \multicolumn{3}{|c|}{ Good/moderate EULAR } \\
\hline Multivariate LR & 489 & 6.8 & $3.8-12.3$ & $<0.001$ & 2.5 & $1.1-5.9$ & 0.035 \\
\hline Univariate LR + PS & 489 & 6.3 & $3.4-11.8$ & $<0.001$ & 1.8 & $0.8-4.1$ & 0.143 \\
\hline Multivariate LR + PS & 489 & 6.4 & $3.4-12.0$ & $<0.001$ & 1.8 & $0.8-4.5$ & 0.182 \\
\hline PS matching & 259 & 6.2 & $3.3-11.6$ & $<0.001$ & 2.2 & $0.93-5.2$ & 0.074 \\
\hline $\begin{array}{l}\text { PS matching + } \\
\text { multivariate LR }\end{array}$ & 259 & 7.8 & $4.0-15.4$ & $<0.001$ & 2.4 & $0.98-6.1$ & 0.056 \\
\hline
\end{tabular}

The odds ratio and 95\% confidence interval (95\% CI) for the effect of tocilizumab versus TNF inhibitors (TNFi) in the considered outcomes are represented according to the statistical methodology used. Multivariate logistic regression (LR) adjusted for other significant confounders as described in Section 2, namely, age, disease duration, number of previous biologics, and baseline disease activity (DAS28 for DAS28/Boolean remission, DAS28 low disease activity (LDA), and EULAR response; CDAI for CDAI remission/LDA; SDAI for SDAI remission/LDA). Propensity scores (PS) predicting biologic class were calculated and incorporated in the analysis, via LR and/or matching (caliper 1:5 with replacement). $P$ value significant at $<0.05$; significant differences highlighted in bold.

other hand, the modelled probability of Boolean remission did not differ between groups and neither did the likelihood of achieving a good/moderate EULAR response when taking into account the propensity score for receiving tocilizumab.

Similar results were obtained by Yoshida et al., with fewer patients per group, in the single centre CABUKI register, where DAS28-ESR remission was more frequent in tocilizumab-treated patients ( $47.8 \%$ versus $25 \%, P=0.006$ ), Boolean remission was similar, and previous biologic therapy had a significant impact on DAS28 remission frequencies [23]. In another study and unlike us, Takahashi et al. found no significant differences in proportions of EULAR good response, DAS28-CRP remission, and LDA between patients treated with tocilizumab or adalimumab, while confirming higher frequencies of EULAR good/moderate response in the tocilizumab group [26]. No adjusted results were reported for these comparisons, an aspect that might help explain these discrepancies [26]. 
We have found an impressive frequency of 57.9\% DAS28 remission at 6 months. These rates are higher than those observed in published RCTs (27\% OPTION [27], 30.1\% RADIATE [28], 39.9\% ADACTA [15], and 40.4\% ACT-RAY [13]) but similar to other observational register-based studies (39-58\% DANBIO [20], 53.3\% Michinoku Tocilizumab Study Group [29], 47.8\% CABUKI [23], and 54.9\% FRAB [21]). The EULAR response rates, based on DAS28, were also similar to those found in RCTs $[13,15,27]$ and observational studies $[20,26]$ that reported them. While it is understandable that the remission rates seen in register-based studies are higher than those observed in RCTs, due to factors such as selection and attrition bias associated with observational studies in a real life setting, it is intriguing that such discrepancies are also seen among different registers. Although the magnitude of the difference in the proportion of patients achieving remission at 6 months is not very large (39\% minimum in DANBIO [20], 57.9\% maximum in Reuma.pt), several aspects can explain these findings. In observational studies, treatment is selected based on objective criteria and also on subjective physician attitudes and expectations, which greatly vary according to country or region. Western European practices certainly differ from Asian ones and even between Portugal (Reuma.pt) and Denmark (DANBIO) factors associated with treatment selection are quite different. Furthermore, visual analogue scale scores are highly subjective, influenced by local cultural factors, and can have a profound impact on the assessment of disease activity. Other potential explanations for these results include genetic factors accounting for variable responses between populations with distinct backgrounds and different frequencies of concomitant treatment with MTX, other DMARDs, and corticosteroids, which might be crucial for suppressing minimal disease activity and attaining remission.

The results of our study confirm that the inclusion of inflammatory markers in the assessment of response to therapy is of extreme importance when analyzing the effectiveness of drugs such as tocilizumab that, through a profound inhibition of IL-6-driven inflammation, markedly suppress ESR and CRP, even within the normal range limits, and might overestimate remission rates, as shown by Smolen and Aletaha [24]. These authors suggest the use of CDAI and SDAI remission/LDA might be more appropriate to compare treatment responses and, in fact, we have found no differences between biologic classes in the overall population analysis [24]. However, in biologic-naïve patients CDAI and SDAI remission were more frequent in the tocilizumab group, with OR of $2.6(P=0.015)$ and $3.0(P=0.007)$, respectively. Similar observations were made after multivariate analyses adjusting for several confounders. It should be noted, though, that the CDAI/SDAI-based analyses forced the exclusion of a significant number of patients due to missing values, and this might somewhat weaken the conclusions. However, sensitivity analysis revealed that simply excluding patients with missing values and performing a univariate analysis for the effect of biologic class on response rates did not yield the same results as the multivariate approaches (data not shown). This suggests that our results are not merely explained by the exclusion of patients in regression models.
We have also found that previous biologic therapy had an important effect on response to treatment. In fact, analysis of the biologic-naïve subgroup of patients revealed higher remission rates, especially for tocilizumab, not only according to DAS28, a finding already reported by others [21, 23], but also with CDAI and SDAI, which differed significantly between biologic class. While it seems reasonable that tocilizumab response is better in biologic-naïve patients compared to those having failed a biologic previously, the differences at 6 months between biologic class in terms of CDAI/SDAI remission/LDA might be at least partly explained by the fact that at baseline these subpopulations were more similar between groups, which was mainly due to less active disease in tocilizumab users and slightly more active disease in the TNFi group (data not shown; the only significant differences were SJC28 and DAS28, still both higher with tocilizumab). On the other hand, for TNFi users, response rates did not differ greatly between the biologicnaive patients and both the overall population and those previously exposed to at least one biologic. This was also seen in the study by Yoshida et al. [23] and, in our opinion, might be related to two findings: first, most of the TNFi group (85.1\%) was naïve to biologic therapy and, thus, the overall group mostly represented the characteristics of the biologicnaïve subpopulation; secondly, biologic-naïve TNFi users had higher baseline DAS28 (5.5 versus 5.1, $P=0.041$ ) and SJC28 (7.1 versus $4.8, P<0.001)$ compared to those that were previously exposed to biologic therapy, thus counteracting the potentially beneficial effect of being a first line user.

Our study has several limitations. Given its observational nature it is prone to different types of confounding, for which we have tried to account for by using propensity scores and multivariate logistic regression. However, residual and unmeasured confounding cannot be avoided and this may limit some of the conclusions. Furthermore, extrapolation of these results to drug efficacy is not possible. More specifically, the fact that there were several baseline differences between biologic class groups suggests that treatment was chosen, at least partially, based on the characteristics of the patients, as would be expected in a clinical practice setting. We used propensity scores to try to adjust for this, although we could not include every baseline variable of interest into the score due to missing data. However, given that RCTs addressing comparative effectiveness of biologics are unlikely to be conducted, observational studies are one of the ways to address this issue.

Other potential limitations should be also taken into account. In this study we provide data at 6 months, which might not be extendable to more prolonged follow-up times. We have also not analysed discontinuation rates or reasons, mainly due to missing values and short follow-up time, and this might limit the translation of conclusions into clinical practice. On the other hand, the fact that we have only included patients with available DAS28 at 0 and 6 months may also imply some degree of bias. Still, considering that Reuma.pt is a clinical practice register, data will be missing due to random reasons such as different likelihood of different clinicians to fill in all fields, rather than due to more or less severe disease activity. Another point to be 
focused is that we only included data on baseline concomitant MTX/corticosteroid treatment and did not assess whether these treatments were discontinued during follow-up. Nevertheless, given the relatively short follow-up and considering the longstanding nature of the disease in most cases, it is reasonable to assume that the combination therapy status did not alter significantly for the majority of the population.

\section{Conclusions}

In conclusion, using data from Reuma.pt, we found that treatment with tocilizumab was associated with higher rates of DAS28 remission/LDA and EULAR good response at 6 months. Similar observations were made also for CDAI and SDAI remission in biologic-naïve patients. Adjusting for other potential confounders confirmed higher response rates with tocilizumab according to DAS28, CDAI, and SDAI criteria. Boolean remission was similar between groups, suggesting that the use of more stringent remission criteria blurs the differences between drug classes. Similar, larger and longer observational studies from other registers are needed to confirm these results and give further insight into therapeutic decisions in the managements of RA patients.

$\begin{array}{ll}\text { Abbreviations } \\ \text { ACPA: } & \text { Anti-citrullinated protein antibodies } \\ \text { ACR: } & \text { American College of Rheumatology } \\ \text { CDAI: } & \text { Clinical disease activity index } \\ \text { CI: } & \text { Confidence interval } \\ \text { CRP: } & \text { C-reactive protein } \\ \text { DAS28: } & \text { Disease activity score-28 joints } \\ \text { DMARDs: } & \text { Disease modifying antirheumatic drugs } \\ \text { ESR: } & \text { Erythrocyte sedimentation rate } \\ \text { EULAR: } & \text { European League Against Rheumatism } \\ \text { HAQ: } & \text { Health assessment questionnaire } \\ \text { LDA: } & \text { Low disease activity } \\ \text { MTX: } & \text { Methotrexate } \\ \text { OR: } & \text { Odds ratio } \\ \text { PGH: } & \text { Patient global health } \\ \text { PhGA: } & \text { Physician global assessment } \\ \text { RA: } & \text { Rheumatoid arthritis } \\ \text { RCTs: } & \text { Randomised clinical trials } \\ \text { Reuma.pt: } & \text { Rheumatic Diseases Portuguese Register } \\ \text { RF: } & \text { Rheumatoid factor } \\ \text { SDAI: } & \text { Simplified disease activity index } \\ \text { SJC28: } & \text { Swollen joint count-28 joints } \\ \text { TNFi: } & \text { Tumour necrosis factor inhibitors } \\ \text { TJC28: } & \text { Tender joint count-28 joints } \\ \text { VAS: } & \text { Visual analogue scale. } \\ & \end{array}$

\section{Conflict of Interests}

Vasco C. Romão has received speaker's fees from Merck Sharp and Dohme. Joaquim Polido-Pereira has received speaker's and/or consulting fees from Roche, Merck Sharp and Dohme, Pfizer, and Tecnimede. Miguel Bernardes has received speaker's and/or consulting fees from Abbvie, Roche,
Merck Sharp and Dohme, Pfizer, and Bristol-Myers Squibb. Filipe Barcelos has received speaker's fees from Merck Sharp and Dohme and travel grants for participation at meetings. José António Pereira da Silva has benefited from speaker's fees and research support from Roche, MSD, Pfizer, and Abbvie. João Eurico Fonseca has received research grants from Abbott, Merck Sharp and Dohme, Pfizer, Roche, and UCB Pharma and speaker's fees and/or consulting fees from Abbvie, Merck Sharp and Dohme, Pfizer, Roche, and UCB Pharma. Helena Canhão has received research grants from Abbott, Merck Sharp and Dohme, Pfizer, Roche, and UCB Pharma. All other authors did not report any relevant financial disclosures.

\section{Authors' Contribution}

Vasco C. Romão has done study conception and design, data collection, data and statistical analysis, paper drafting, critical revision, and final approval of paper. Maria José Santos has done data collection, critical revision, and final approval of the paper. Joaquim Polido-Pereira has done data collection, critical revision, and final approval of the paper. Cátia Duarte has done data collection, critical revision, and final approval of the paper. Patrícia Nero has done data collection, critical revision, and final approval of the paper. Cláudia Miguel has done data collection, critical revision, and final approval of the paper. José António Costa has done data collection, critical revision, and final approval of the paper. Miguel Bernardes has done data collection, critical revision, and final approval of the paper. Fernando M. Pimentel-Santos has done data collection, critical revision, and final approval of the paper. Filipe Barcelos has done data collection, critical revision, and final approval of the paper. Lúcia Costa has done data collection, critical revision, and final approval of the paper. José António Melo Gomes has done data collection, critical revision, and final approval of the paper. José Alberto Pereira da Silva has done data collection, critical revision, and final approval of the paper. Jaime Cunha Branco has done data collection, critical revision, and final approval of the paper. José Canas da Silva has done data collection, critical revision, and final approval of the paper. José António Pereira da Silva has done data collection, critical revision, and final approval of the paper. João Eurico Fonseca has done study conception and design, data collection, data analysis, paper drafting, critical revision, and final approval of paper. Helena Canhão has done study conception and design, data collection, data and statistical analysis, paper drafting, critical revision, and final approval of paper. All authors read and approved the final paper.

\section{Acknowledgments}

Reuma.pt has been supported by unrestricted grants from Abbvie, Merck Sharp and Dohme, Pfizer, UCB Pharma, and Roche. The authors would like to acknowledge Fernando Martins, IT, from the Portuguese Society of Rheumatology for his technical support and management of Reuma.pt data. 


\section{References}

[1] P. C. Taylor and M. Feldmann, "Anti-TNF biologic agents: still the therapy of choice for rheumatoid arthritis," Nature Reviews Rheumatology, vol. 5, no. 10, pp. 578-582, 2009.

[2] M. C. Hochberg, J. K. Tracy, M. Hawkins-Holt, and R. H. Flores, "Comparison of the efficacy of the tumour necrosis factor $\alpha$ blocking agents adalimumab, etanercept, and infliximab when added to methotrexate in patients with active rheumatoid arthritis," Annals of the Rheumatic Diseases, vol. 62, Supplement 2, pp. 13-16, 2003.

[3] K. J. Aaltonen, L. M. Virkki, A. Malmivaara, Y. T. Konttinen, D. C. Nordström, and M. Blom, "Systematic review and metaanalysis of the efficacy and safety of existing TNF blocking agents in treatment of rheumatoid arthritis," PLOS ONE, vol. 7, no. 1, Article ID e30275, 2012.

[4] H. Canhão, A. M. Rodrigues, A. F. Mourão et al., "Comparative effectiveness and predictors of response to tumour necrosis factor inhibitor therapies in rheumatoid arthritis," Rheumatology, vol. 51, no. 11, Article ID kes184, pp. 2020-2026, 2012.

[5] J. D. Greenberg, G. Reed, D. Decktor et al., "A comparative effectiveness study of adalimumab, etanercept and infliximab in biologically naive and switched rheumatoid arthritis patients: results from the US CORRONA registry," Annals of the Rheumatic Diseases, vol. 71, no. 7, pp. 1134-1142, 2012.

[6] K. L. Hyrich, K. D. Watson, A. J. Silman, and D. P. M. Symmons, "Predictors of response to anti-TNF- $\alpha$ therapy among patients with rheumatoid arthritis: results from the British Society for Rheumatology Biologics Register," Rheumatology, vol. 45, no. 12, pp. 1558-1565, 2006.

[7] J. S. Smolen, R. Landewé, F. C. Breedveld et al., "EULAR recommendations for the management of rheumatoid arthritis with synthetic and biological disease-modifying antirheumatic drugs: 2013 update," Annals of the Rheumatic Diseases, vol. 73, no. 3, pp. 492-509, 2014.

[8] J. E. Fonseca, M. Bernardes, H. Canhão et al., "Portuguese guide lines for the use of biological agents in rheumatoid arthritisoctober 2011 update," Acta Reumatologica Portuguesa, vol. 36, no. 4, pp. 385-388, 2011.

[9] I. Flouri, T. E. Markatseli, P. V. Voulgari et al., "Comparative effectiveness and survival of infliximab, adalimumab, and etanercept for rheumatoid arthritis patients in the Hellenic Registry of Biologics: low rates of remission and 5-year drug survival," Seminars in Arthritis and Rheumatism, vol. 43, no. 4, pp. 447457, 2014.

[10] J. A. Markenson, A. Gibofsky, W. R. Palmer et al., "Persistence with anti-tumor necrosis factor therapies in patients with rheumatoid arthritis: observations from the RADIUS registry," The Journal of Rheumatology, vol. 38, no. 7, pp. 1273-1281, 2011.

[11] C. Salliot, A. Finckh, W. Katchamart et al., "Indirect comparisons of the efficacy of biological antirheumatic agents in rheumatoid arthritis in patients with an inadequate response to conventional disease-modifying antirheumatic drugs or to an anti-tumour necrosis factor agent: a meta-analysis," Annals of the Rheumatic Diseases, vol. 70, no. 2, pp. 266-271, 2011.

[12] M. Schoels, D. Aletaha, J. S. Smolen, and J. B. Wong, "Comparative effectiveness and safety of biological treatment options after tumour necrosis factor $\alpha$ inhibitor failure in rheumatoid arthritis: systematic review and indirect pairwise metaanalysis," Annals of the Rheumatic Diseases, vol. 71, no. 8, pp. 1303-1308, 2012.
[13] M. Dougados, K. Kissel, T. Sheeran et al., "Adding tocilizumab or switching to tocilizumab monotherapy in methotrexate inadequate responders: 24 -week symptomatic and structural results of a 2-year randomised controlled strategy trial in rheumatoid arthritis (ACT-RAY)," Annals of the Rheumatic Diseases, vol. 72, no. 1, pp. 43-50, 2013.

[14] G. Jones, A. Sebba, J. Gu et al., "Comparison of tocilizumab monotherapy versus methotrexate monotherapy in patients with moderate to severe rheumatoid arthritis: the AMBITION study," Annals of the Rheumatic Diseases, vol. 69, no. 1, pp. 8896, 2010.

[15] C. Gabay, P. Emery, R. van Vollenhoven et al., “Tocilizumab monotherapy versus adalimumab monotherapy for treatment of rheumatoid arthritis (ADACTA): a randomised, doubleblind, controlled phase 4 trial," The Lancet, vol. 381, no. 9877, pp. 1541-1550, 2013.

[16] G. J. D. Bergman, M. C. Hochberg, M. Boers, N. Wintfeld, A. Kielhorn, and J. P. Jansen, "Indirect comparison of tocilizumab and other biologic agents in patients with rheumatoid arthritis and inadequate response to disease-modifying antirheumatic drugs," Seminars in Arthritis and Rheumatism, vol. 39, no. 6, pp. 425-441, 2010.

[17] E. Turkstra, S.-K. Ng, and P. A. Scuffham, "A mixed treatment comparison of the short-term efficacy of biologic disease modifying anti-rheumatic drugs in established rheumatoid arthritis," Current Medical Research and Opinion, vol. 27, no. 10, pp. 18851897, 2011.

[18] A. Pierreisnard, N. Issa, T. Barnetche, C. Richez, and T. Schaeverbeke, "Meta-analysis of clinical and radiological efficacy of biologics in rheumatoid arthritis patients naive or inadequately responsive to methotrexate," Joint Bone Spine, vol. 80, no. 4, pp. 386-392, 2013.

[19] M. Gallego-Galisteo, A. Villa-Rubio, E. Alegre-Del Rey, E. Márquez-Fernández, and J. J. Ramos-Báez, "Indirect comparison of biological treatments in refractory rheumatoid arthritis," Journal of Clinical Pharmacy and Therapeutics, vol. 37, no. 3, pp. 301-307, 2012.

[20] H. C. Leffers, M. Østergaard, B. Glintborg et al., "Efficacy of abatacept and tocilizumab in patients with rheumatoid arthritis treated in clinical practice: results from the nationwide Danish DANBIO registry," Annals of the Rheumatic Diseases, vol. 70, no. 7, pp. 1216-1222, 2011.

[21] Y. Nakashima, M. Kondo, T. Fukuda et al., "Remission in patients with active rheumatoid arthritis by tocilizumab treatment in routine clinical practice: results from 3 years of prospectively registered data," Modern Rheumatology, vol. 24, pp. 258-264, 2014.

[22] G. R. Burmester, E. Feist, H. Kellner, J. Braun, C. IkingKonert, and A. Rubbert-Roth, "Effectiveness and safety of the interleukin 6-receptor antagonist tocilizumab after 4 and 24 weeks in patients with active rheumatoid arthritis: the first phase IIIb real-life study (TAMARA)," Annals of the Rheumatic Diseases, vol. 70, no. 5, pp. 755-759, 2011.

[23] K. Yoshida, Y. Tokuda, H. Oshikawa et al., "An observational study of tocilizumab and TNF- $\alpha$ inhibitor use in a Japanese community hospital: different remission rates, similar drug survival and safety," Rheumatology, vol. 50, no. 11, pp. 20932099, 2011.

[24] J. S. Smolen and D. Aletaha, "Interleukin-6 receptor inhibition with tocilizumab and attainment of disease remission in rheumatoid arthritis: the role of acute-phase reactants," Arthritis and Rheumatism, vol. 63, no. 1, pp. 43-52, 2011. 
[25] H. Canhão, A. Faustino, F. Martins, and J. E. Fonseca, "Reuma. PT-the rheumatic diseases portuguese register," Acta Reumatologica Portuguesa, vol. 36, no. 1, pp. 45-56, 2011.

[26] N. Takahashi, T. Kojima, A. Kaneko et al., "Clinical efficacy of abatacept compared to adalimumab and tocilizumab in rheumatoid arthritis patients with high disease activity," Clinical Rheumatology, vol. 33, no. 1, pp. 39-47, 2014.

[27] J. S. Smolen, A. Beaulieu, A. Rubbert-Roth et al., "Effect of interleukin-6 receptor inhibition with tocilizumab in patients with rheumatoid arthritis (OPTION study): a double-blind, placebo-controlled, randomised trial," The Lancet, vol. 371, no. 9617, pp. 987-997, 2008.

[28] P. Emery, E. Keystone, H. P. Tony et al., "IL-6 receptor inhibition with tocilizumab improves treatment outcomes in patients with rheumatoid arthritis refractory to anti-tumour necrosis factor biologicals: results from a 24 -week multicentre randomised placebo-controlled trial," Annals of the Rheumatic Diseases, vol. 67, no. 11, pp. 1516-1523, 2008.

[29] Y. Hirabayashi and T. Ishii, "The DAS28-ESR cutoff value necessary to achieve remission under the new Boolean-based remission criteria in patients receiving tocilizumab," Clinical Rheumatology, vol. 32, no. 1, pp. 123-127, 2013. 


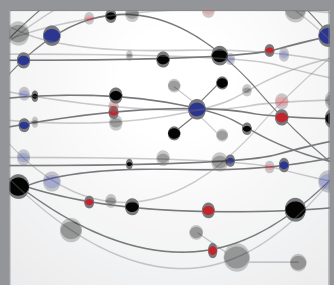

The Scientific World Journal
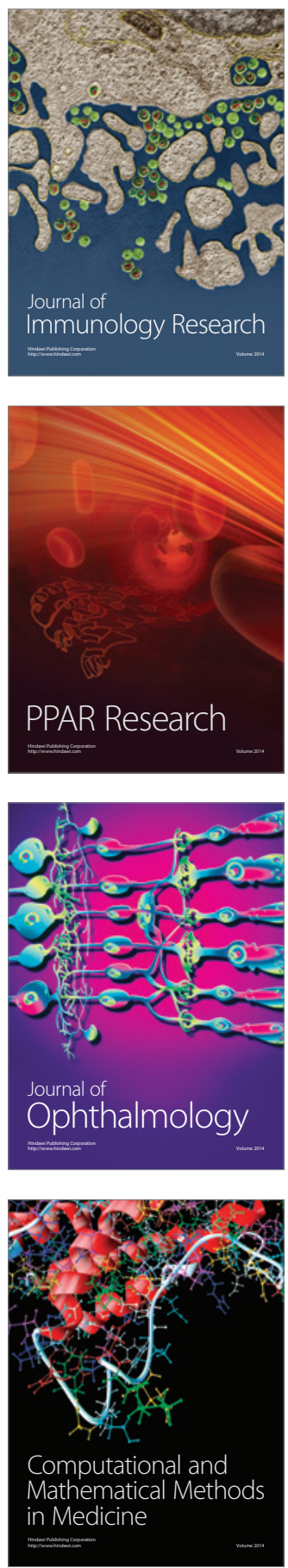

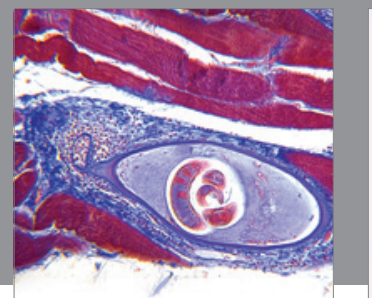

Gastroenterology

Research and Practice
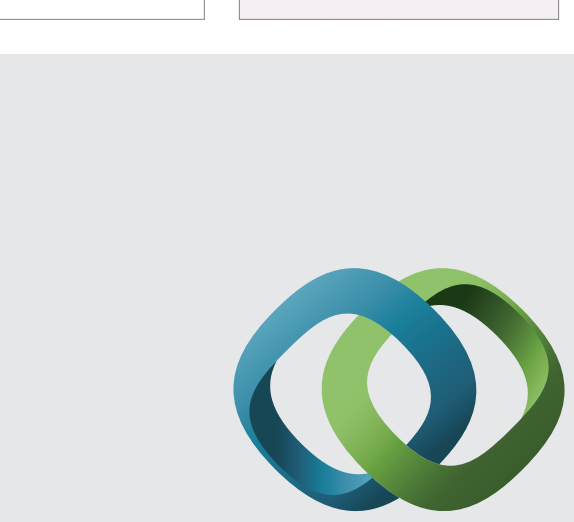

\section{Hindawi}

Submit your manuscripts at

http://www.hindawi.com
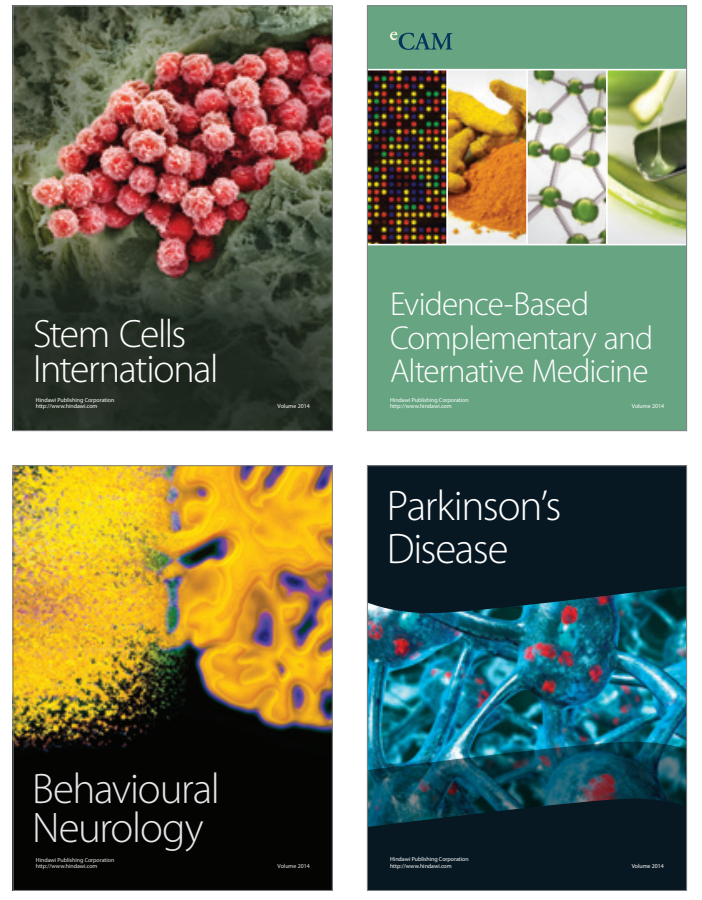
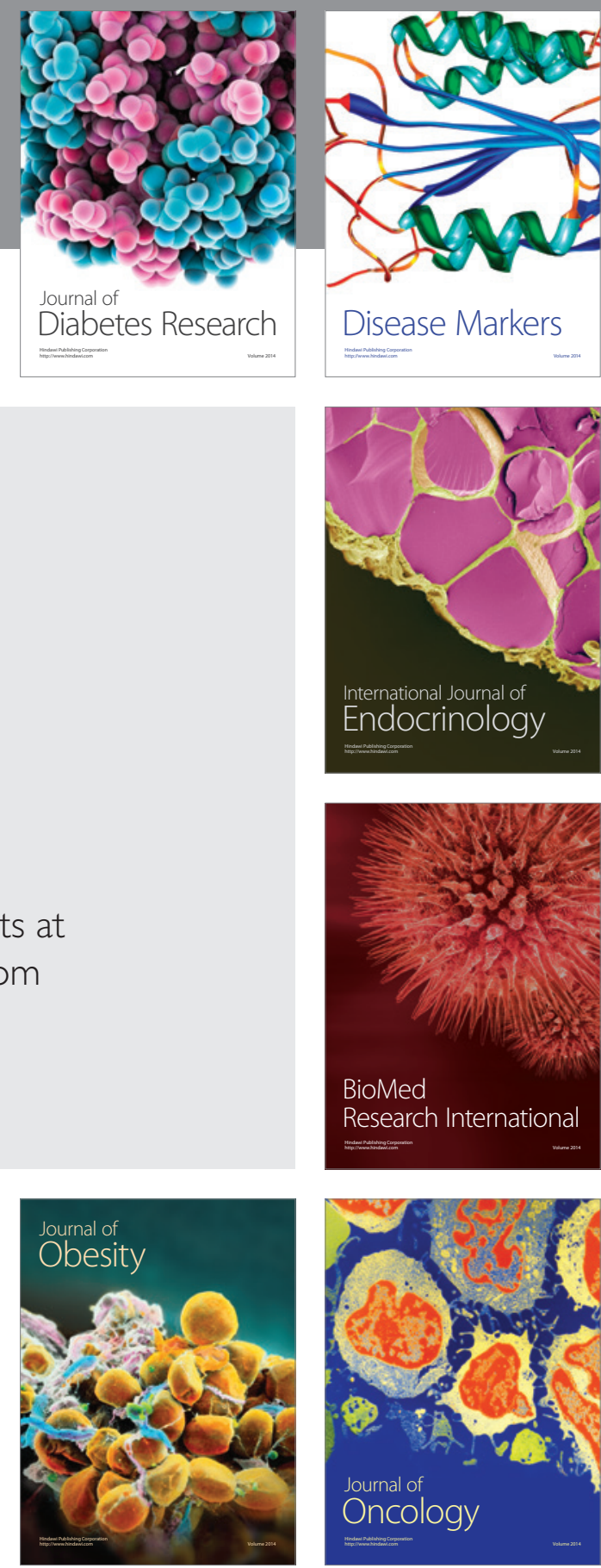

Disease Markers
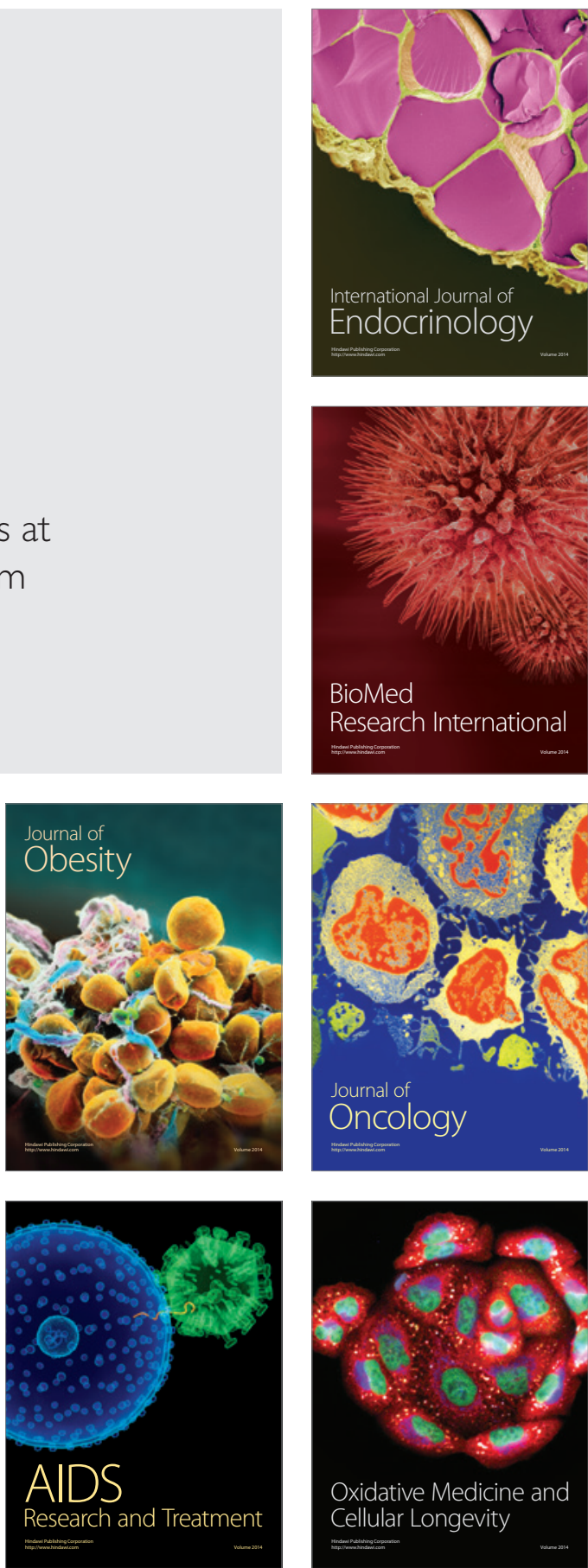